IOS Press

\title{
Tumor-infiltrating lymphocytes are associated with $\beta$-catenin overexpression in breast
}

\section{cancer}

\author{
Xingcong Ma ${ }^{\mathrm{a}}$, Xiaoyao Zhao ${ }^{\mathrm{a}}$, Wanjun Yan ${ }^{\mathrm{a}}$, Jun Yang ${ }^{\mathrm{b}}$, Xixi Zhao ${ }^{\mathrm{a}}$, Hong Zhang ${ }^{\mathrm{a}}$, Yuxin Hui ${ }^{\mathrm{c}}$ and \\ Shuqun Zhang, ${ }^{\mathrm{a}, *}$ \\ ${ }^{a}$ Department of Oncology, The Second Affiliated Hospital of Xi'an Jiaotong University, Xi'an 710004, Shaanxi, \\ China \\ ${ }^{\mathrm{b}}$ Department of Pathology, The Second Affiliated Hospital of Xi'an Jiaotong University, Xi'an 710004, Shaanxi, \\ China \\ ${ }^{\mathrm{c}}$ School of Traditional Chinese Medicine, Hunan University of Chinese Medicine, Changsha 410208, Hunan, \\ China
}

\begin{abstract}
.
BACKGROUND: Inhibition of lymphocytes infiltration and activity may impair antitumor immune response and limit treatment responsiveness. Wnt/ $\beta$-catenin pathway has been suggested to contribute to immune evasion in tumor by suppressing the function of immune cells and excluding T cell infiltration. However, the effects of Wnt/ $\beta$-catenin on TILs recruitment remain controversial. OBJECTIVE: We aimed to investigate whether intratumoral $\mathrm{Wnt} / \beta$-catenin signaling could affect the lymphocyte infiltration in breast cancer.

METHODS: The distribution of stromal TILs, $\mathrm{CD}^{+}$and FOXP3 ${ }^{+}$TIL subsets, and the expression of $\beta$-catenin were separately assessed on consecutive sections of 96 breast cancer specimens.

RESULTS: Both stromal infiltrated TILs and $\beta$-catenin expression were upregulated in hormone receptor negative HER2enriched and TNBC subtypes. Furthermore, high levels of stromal TILs as well as $\mathrm{CD}^{+}$or FOXP3 $^{+} \mathrm{TIL}$ subsets were associated with $\beta$-catenin overexpression by breast cancer, respectively.

CONCLUSIONS: For the first time, we demonstrated that rather than excluding lymphocytes infiltration as reported in melanoma, high levels of TILs were associated with $\beta$-catenin overexpression in BC. Wnt $/ \beta$-catenin signaling may play a critical role in BC immunity, particularly in HER2-enriched and triple negative BC, and may serve as a potential target for regulating immune infiltrates in breast cancer.
\end{abstract}

Keywords: Tumor infiltrating lymphocytes, Wnt $/ \beta$-catenin signaling, $\mathrm{CD}^{+}{ }^{+}$TILs, FOXP3 ${ }^{+}$TILs, breast cancer

\section{Introduction}

Despite the improvement of its overall 5-year survival rate in the past 3 decades, breast cancer is still the most prevalent cancer among females worldwide [1]. It is also the leading cause of cancer death among women in less developed regions and the second cause

\footnotetext{
${ }^{*}$ Corresponding author: Shuqun Zhang, Department of Oncology, The Second Affiliated Hospital of Xi'an Jiaotong University, No. 157, West 5th Road, Xi' an 710004, Shaanxi, China. E-mail: shuqun_zhang1971@163.com.
}

of cancer death in more developed regions [2], posing great threat to women's health. The interaction between tumor cells and immune system is critical for the development and progression of cancer [3]. Although breast cancer (BC) is not traditionally considered as immunogenic, an increasing number of retrospective and prospective studies have shown that high level of lymphocytes infiltration in BC is associated with improved outcome of patients, particularly in triple negative and HER2-enriched early breast cancer [4-6]. Moreover, the presence of TILs could favorably influence treatment responsiveness to neoadju-

ISSN 1574-0153/18/\$35.00 (C) 2018 - IOS Press and the authors. All rights reserved

This article is published online with Open Access and distributed under the terms of the Creative Commons Attribution Non-Commercial License (CC BY-NC 4.0). 
vant chemotherapy [7]. An association between higher levels of TILs and increased trastuzumab benefit in HER $2^{+}$breast cancer has also been reported [8]. Accordingly, inhibition of lymphocytes infiltration and activity in the tumor microenvironment may impair antitumor immune response and limit treatment responsiveness in breast cancer.

Wnt pathway plays a key role in the development and function of hematopoietic system [9-11]. In peripheral immunity, canonical $\mathrm{Wnt} / \beta$-catenin signaling is critical for the polarization, differentiation and survival of mature $\mathrm{T}$ lymphocytes [12]. It has been reported that the activation of $\mathrm{Wnt} / \beta$-catenin pathway could negatively regulate the naive-to-effector $\mathrm{T}$ cell differentiation in human $\mathrm{T}$ lymphocytes $[13$, 14]. Wnt $/ \beta$-catenin signaling also inhibits the proinflammatory cytokine induction of dendritic cells (DCs) in response to toll like receptor ligands and promotes DC generation of FOXP3 ${ }^{+}$(forkhead box $\mathrm{P} 3$ ) regulatory $\mathrm{T}$ cells, thus reprogramming $\mathrm{DC}$ responses for immune tolerance [15]. Wnt signaling is frequently activated in various cancers [16], and their immune suppressive and tolerogenic effects on $\mathrm{T}$ cells and DCs may contribute to tumor immune evasion and cancer progression. In melanoma, accumulation of $\beta$ catenin in tumor cells and tissues upregulated IL-10 expression by directly binding to the IL-10 promoter, which impaired DC maturation and induced regulatory phenotype among DCs. Moreover, the anti-tumor effect of melanoma-specific cytotoxic $\mathrm{CD}^{+} \mathrm{T}$ cells was inhibited by $\mathrm{Wnt} / \beta$-catenin activity in vitro and in vivo [17]. Emerging evidence from clinical data suggest that immunotherapeutic strategies, including checkpoint blockade, are predominantly effective in patients with a pre-existing $\mathrm{T}$ cell-inflamed tumor microenvironment [18-20]. Spranger and colleagues [21] reported that melanoma intrinsic $\mathrm{Wnt} / \beta$-catenin signaling prevented T-cell infiltration in tumor microenvironment and resulted in the resistance to anti-PDL1/anti-CTLA-4 monoclonal antibody therapy. However, the effects of $\mathrm{Wnt} / \beta$-catenin on tumor immunity remain controversial. Wnt $\beta$-catenin signaling is proved to be required for the reconstitution and quiescence of hematopoietic stem cells (HSC) [22,23]. In a mouse model, activation of the Wnt pathway prevented $\mathrm{CD}^{+} \mathrm{T}$ cells from differentiating into effector $\mathrm{T}$ cells, and generated a population of $\mathrm{CD}^{+} \mathrm{T}$ cell subset showing a young/memory phenotype similar to stem cell memory $\mathrm{T}$ cells $\left(\mathrm{T}_{S C M}\right)$, which showed higher proliferation and antitumor activity than central memory $\mathrm{T}$ cells $\left(\mathrm{T}_{C M}\right)$ or effector memory $\mathrm{T}$ cells $\left(\mathrm{T}_{C M}\right)$. Fur- thermore, $\mathrm{Wnt} / \beta$-catenin signaling improved the persistence of human $\mathrm{CD} 8^{+} \mathrm{T}$ cells by overexpression of Bcl-2 and absence of active caspase-3 [24]. These findings revealed that $\mathrm{Wnt} / \beta$-catenin pathway might contribute to the maintenance of stemness in mature $\mathrm{CD} 8^{+}$ $\mathrm{T}$ cells, indicating the potential value of $\mathrm{Wnt} / \beta$-catenin pathway in adoptive $\mathrm{T}$ cell therapy for cancer. Taken together, whether Wnt/ $\beta$-catenin pathway plays a positive or negative role in anti-tumor immunity is open to question and requires further investigation.

High $\beta$-catenin activity has been reported to correlate with poor prognosis and tumor progression in breast cancer $[25,26]$. Our previous findings also suggest that $\mathrm{Wnt} / \beta$-catenin pathway is abnormally activated in breast cancer, and may be of mechanistic and pharmatheutical significance in the disease [27]. However, the involvement of $\mathrm{Wnt} / \beta$-catenin signaling in tumor immune microenvironment has not been clearly established.

In this study, we seek to further explore the clinicalpathological factors that affect $\mathrm{T}$ lymphocytes infiltration in breast cancer and the correlation between components of tumor inflammatory infiltrates and $\mathrm{Wnt} / \beta$ catenin pathway activity, as measured by $\beta$-catenin expression in tumor tissues. Various reports have suggested that infiltration of $\mathrm{CD}^{+}{ }^{+} \mathrm{T}$ cells in breast cancer has antitumor activity as judged by their favorable effect on patients' survival, while high levels of FOXP3 ${ }^{+}$ Tregs predict reduced survival in overall breast cancer with exception for TNBC [28-32], indicating clinical significance for these two subsets. Thus we further assessed the infiltration of these two TIL subsets and their association with $\beta$-catenin expression in breast cancer. Here, we provide the novel findings that rather than excluding TILs from tumor microenvironment, activation of intrinsic $\mathrm{Wnt} / \beta$-catenin signaling in breast cancer is positively associated with high levels of total lymphocyte infiltration as well as the number of $\mathrm{CD}^{+}$or FOXP3 ${ }^{+}$TIL subsets.

\section{Materials and methods}

\subsection{Patients' specimen and clinicopathological data}

Female patients with first diagnosed, primary operable breast carcinoma, without clinical distant metastasis, no history of receiving neoadjuvant chemotherapy or preoperative radiation therapy were considered for inclusion in this study. A total number of 96 paraffinembedded tumor samples were obtained from primary 
breast cancer patients. Ninety-six tumor samples were reported as infiltrating ductal or lobular breast carcinoma. Median age of the patients is 52 years old (range 28-77). Detailed clinicopathological data of the tumor samples were retrieved from the routine reports of Department of Pathology, the Second Affiliated Hospital of Xi' an Jiaotong University. Immunohistochemical analyses were performed by qualified pathologists, and the cutoffs for ER, PR were 1\% [33]. The criteria used to determine the HER2 status was in accordance with the 2013 ASCO/CAP guideline [34]. In samples showing IHC $2^{+}$(equivocal), fluorescent in situ hybridization (FISH) amplification was applied to determine HER2 status. This study was reviewed and approved by the ethics committee of Xi' an Jiaotong University. All the participants were informed and signed consent for the use of their biological tissues.

\subsection{Histopathologic analysis of TILs}

Full-face breast cancer slides ( $5 \mu \mathrm{m}$ thickness) were stained with hematoxylin-eosin (H\&E) using standard procedures. TILs in the stromal compartment were defined and analyzed according to the standardization and guidelines for TILs assessment described by Salgado et al. [35]. Histopathologic evaluation of Str-TILs was performed separately by two experienced pathologists in the Department of Pathology of our hospital. They both were blinded to the clinicopathological information collected in this study. Results would be discussed if substantial discrepancies occur. The results were reported as three categories: TILs Low (\%StrTIL $<10 \%)$, TILs Intermediate $(\%$ Str-TIL $=10-40 \%)$ and TILs High ( $\%$ Str-TIL $\geqslant 40 \%)$. These cutoffs were also adopted from the same guidelines mentioned previously [30].

\subsection{Immunohistochemical staining}

The expression of $\beta$-catenin protein by tumor tissue and populations of $\mathrm{CD}^{+}{ }^{+} \mathrm{T}$ cells and $\mathrm{FOXP} 3^{+}$Tregs dispersed in the cancer stroma were determined by immunohistochemical staining with the IHC Detection Kit (CWBiotech, Beijing, China) on $5 \mu$ m consecutive paraffin-embedded tissue slides, respectively. Antigen retrieval with citrate buffer was included. Primary monoclonal antibodies against $\beta$-catenin (ab32572, clone E247, Abcam, Cambridge, MA; 1:500 dilution), CD8 $\alpha$ (\#70306, clone C8/144B, CST, Danvers, MA; 1:200 dilution) and FOXP3 (ab20034, clone 236A/E7, Abcam, Cambridge, MA; 1:100 dilution) were used according to the protocol of the manufacturer. Slides that were incubated with phosphate-buffered saline (PBS) instead of primary antibody served as negative control. Images of the full-face slides were taken using the automatic digital slide scanner (Zeiss Axio Scan .Z1, Jena, Germany).

\subsection{Immunohistochemistry evaluation}

$\beta$-catenin expression and the number of $\mathrm{CD}^{+}$or $\mathrm{FOXP}^{+} \mathrm{T}$ cells were evaluated independently by two qualified pathologists, who were blinded to the clinicopathological data of the slides. Joint re-assessment would be made for the final consensus. For each slide, ten non-overlapping high-power fields (x400 magnification) in the tumor stroma were randomly chosen for evaluation.

All tumors slides were assessed for both intensity (score 1 to 3, Fig. 1), and the proportion of cells staining positive in the nucleus and/or cytoplasm. Score of 0 if $<5 \%$ of morphologically unequivocal tumor cells discretely expressed cytoplasmic/nuclear $\beta$ catenin; score $1=6-25 \%$ positive cells; score $2=26$ $50 \%$ positive cells; score $3=51-75 \%$ positive cells; score $4=>75 \%$ of tumor cells expressed cytoplasmic/nuclear $\beta$-catenin. A histoscore $(\mathrm{H})$ was calculated by multiplying the scores of percentage of positively stained cells with the score of staining intensity [36]. The final staining score was defined according to the $\mathrm{H}$ score: score of 1 if $\mathrm{H}=0-1$; score of 2 if $\mathrm{H}=2$ 4; score of 3 if $\mathrm{H}=6$ or 8 ; score of 4 if $\mathrm{H}=9$ or 12. Final staining score $0-2$ was considered as cytoplasmic/nuclear $\beta$-catenin negative, and score 3-4 was defined as cytoplasmic/nuclear $\beta$-catenin positive.

$\mathrm{CD}^{+} \mathrm{T}$ cells are mainly stained in the membrane and the nuclear (Fig. 2A). For FOXP3 detection, darkbrown colored nuclear staining was defined as positive (Fig. 2B). The average counts of stromal CD8 positive or FOXP3 positive lymphocytes were recorded and accepted as the infiltration of $\mathrm{CD}^{+}$cytotoxic $\mathrm{T}$ cells and FOXP3 ${ }^{+}$Tregs, respectively [37].

\subsection{Statistical analyses}

Associations between TILs, $\mathrm{CD}^{+}$or $\mathrm{FOXP}^{+} \mathrm{T}$ cells counts, cytoplasmic/nuclear $\beta$-catenin expression and clinicopathological parameters were evaluated using Pearson Chi-square $\left(\chi^{2}\right)$ test or Fisher's exact tests. Kruskal-Wallis test and Pearson Correlation test were applied for evaluating the correlation between TILs, $\mathrm{CD}^{+}{ }^{+}$or $\mathrm{FOXP}^{+}{ }^{+} \mathrm{T}$ cells counts and $\beta$-catenin ex- 

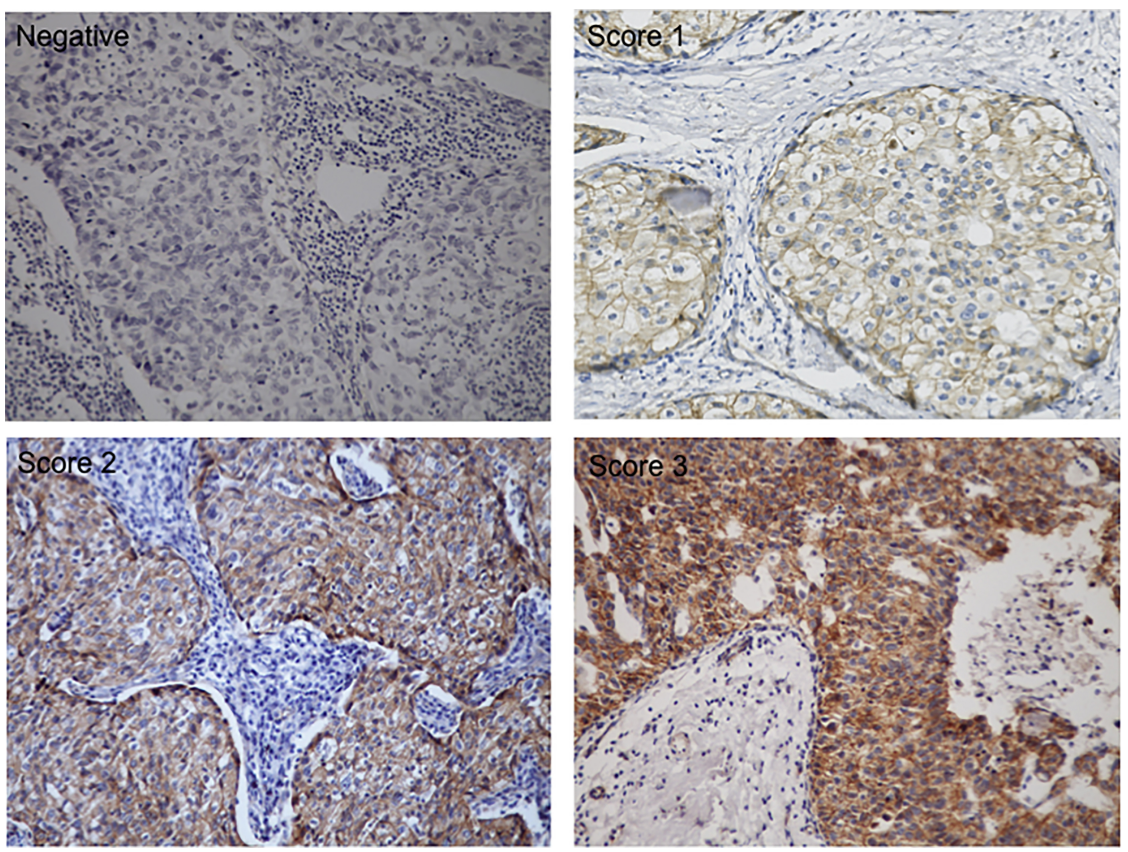

Fig. 1. Representative images of $\beta$-catenin expression in breast cancer sections (magnification, $\mathrm{x} 200$ ). Scores of 1 to 3 were defined according to the immunohistochemical intensity of $\beta$-catenin.
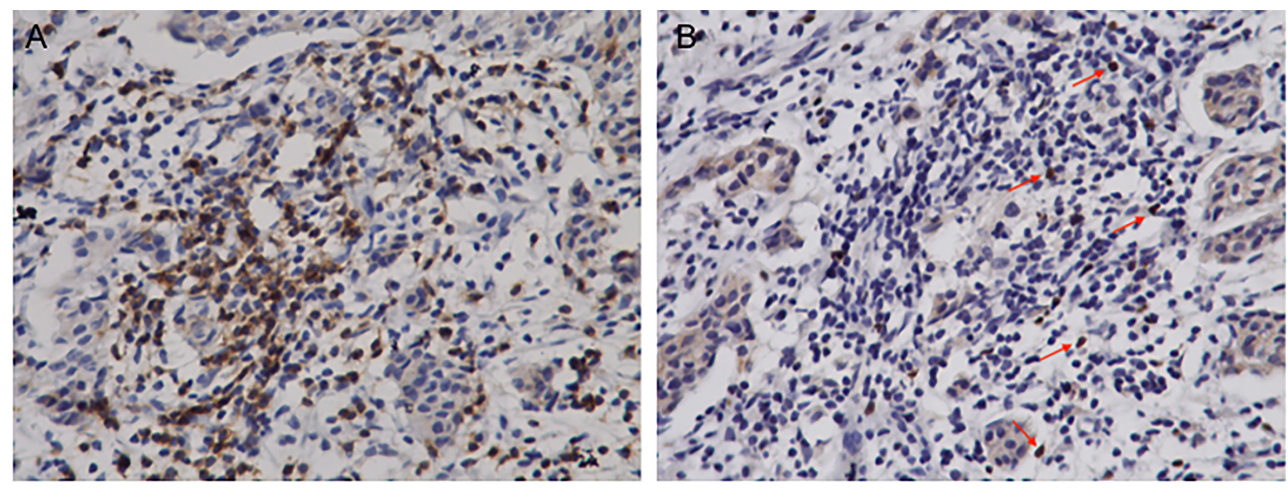

Fig. 2. Representative immunohistochemistry staining of stromal $\mathrm{CD} 8^{+}$and $\mathrm{FOXP} 3^{+} \mathrm{T}$ cell infiltrates in breast cancer (magnification, $\mathrm{x} 400$ ) Consecutive sections were used for immunohistochemical detection of FOXP3 ${ }^{+}(\mathrm{A})$ and $\mathrm{CD}^{+}$cells (B).

pression, respectively. All statistical analysis was performed using SPSS 20.0 (IBM Corporation, Armonk, NY, USA) statistics software. The significance level was taken to be 0.05 , and all p-values were two-sided.

\section{Results}

\subsection{Lymphocytes infiltration in breast cancer correlates with tumor grade and ER/PR status}

The clinicopathological information of 96 breast cancer patients recruited in this study is summarized in Table 1. Fifty-two patients $(54.2 \%)$ presented with clinically detectable axillary lymph node metastasis at diagnosis. Fifty-six of patients $(58.3 \%)$ had moderately (grade II) or poorly differentiated (grade III) tumors, and 84 patients $(87.5 \%)$ presented with stage II or III tumors. According to the criteria previously described [35], we divided the distribution of stromal TILs into three levels based on the percentage of TILs that occupied the stromal areas. Increased lymphocytes infiltration in tumor stroma was significantly associated with higher histological grade $(p=$ 0.020 ). Sixty percent of tumors presented with low histological grade showed low density of TILs. By 
Table 1

Correlation analyses between the presence of stromal TILs and clinicopathologic parameters in 96 primary breast cancer patients

\begin{tabular}{|c|c|c|c|c|c|}
\hline & \multirow{2}{*}{$\begin{array}{c}\text { Number of } \\
\text { patients }(\%)\end{array}$} & \multicolumn{3}{|c|}{ TILs } & \multirow[b]{2}{*}{$\mathrm{p}$} \\
\hline & & Low $(<10 \%)$ & intermediate $(10-40 \%)$ & High $(\geqslant 40 \%)$ & \\
\hline \multicolumn{6}{|l|}{ Age (years) } \\
\hline$\leqslant 50$ & $44(45.8)$ & $24(54.5)$ & $17(38.6)$ & $3(6.8)$ & \multirow[t]{2}{*}{0.773} \\
\hline$>50$ & $52(54.2)$ & $24(46.2)$ & $24(46.2)$ & $4(7.6)$ & \\
\hline \multicolumn{6}{|c|}{ Tumor size (mm) } \\
\hline$\leqslant 20$ & $35(36.5)$ & $16(45.7)$ & $18(51.4)$ & $1(2.9)$ & \multirow[t]{3}{*}{0.372} \\
\hline $21-50$ & $56(58.3)$ & $30(53.6)$ & $21(37.5)$ & $5(8.9)$ & \\
\hline$>50$ & $5(5.20)$ & $2(40.0)$ & $2(40.0)$ & $1(20.0)$ & \\
\hline \multicolumn{6}{|l|}{ Grade } \\
\hline II & $40(41.7)$ & $24(60.0)$ & $12(30.0)$ & $4(10.0)$ & \multirow[t]{3}{*}{0.020} \\
\hline II & $32(33.3)$ & $9(28.1)$ & $16(50.0)$ & $7(21.9)$ & \\
\hline III & $24(25.0)$ & $6(25.0)$ & $11(45.8)$ & $7(29.2)$ & \\
\hline \multicolumn{6}{|l|}{ Nodal status } \\
\hline Negative & $44(45.8)$ & $23(52.3)$ & $17(38.6)$ & $4(9.1)$ & \multirow[t]{2}{*}{0.736} \\
\hline Positive & $52(54.2)$ & $25(48.1)$ & $24(46.2)$ & $3(5.7)$ & \\
\hline \multicolumn{6}{|l|}{ HER2 } \\
\hline Negative & $56(58.3)$ & $32(57.1)$ & $20(35.7)$ & $4(7.2)$ & \multirow[t]{2}{*}{0.216} \\
\hline Positive & $40(41.7)$ & $16(40.0)$ & $21(52.5)$ & $3(7.5)$ & \\
\hline \multicolumn{6}{|l|}{ ER } \\
\hline Negative & $28(29.2)$ & $7(25.0)$ & $16(57.1)$ & $5(17.9)$ & \multirow[t]{2}{*}{0.001} \\
\hline Positive & $68(70.8)$ & $41(60.3)$ & $25(36.8)$ & $2(2.9)$ & \\
\hline \multicolumn{6}{|l|}{ PR } \\
\hline Negative & $42(43.7)$ & $15(35.7)$ & $22(52.4)$ & 5 (11.9) & \multirow[t]{2}{*}{0.029} \\
\hline Positive & $54(56.3)$ & $33(61.1)$ & $19(35.2)$ & $2(3.7)$ & \\
\hline \multicolumn{6}{|l|}{ Stage } \\
\hline I & $12(12.5)$ & $5(41.7)$ & $7(58.3)$ & 0 & \multirow[t]{3}{*}{0.346} \\
\hline II & $63(65.6)$ & $30(47.6)$ & $26(41.3)$ & $7(11.1)$ & \\
\hline III & $21(21.9)$ & $13(61.9)$ & $8(38.1)$ & 0 & \\
\hline
\end{tabular}

contrast, more than $70 \%$ of the poorly differenced breast tumors (grade II and III) have higher levels of lymphocytes infiltration. Moreover, significant correlations were recorded for both ER $(p=0.001)$ and PR $(p=0.029)$ status in breast cancer. Seventy-five percent among ER negative breast tumors showed intermediate to high level of lymphocytes infiltration while in most ER positive tumors $(60.3 \%)$, the percentage of stromal TILs was low $(<10 \%)$. Similar to ER status, PR positive tumors tend to have less lymphocytes infiltration, while significantly higher density of stromal TILs was observed in the PR negative breast cancer (64.3\%). No significant association was identified between HER2 overexpression and stromal TILs (Table 1).

\subsection{Both stromal lymphocytes infiltration and $\beta$-catenin expression differs between the molecular subtypes of breast cancer}

Breast cancer has been classified into four molecular subtypes: luminal types A, luminal types B, HER2enriched and triple-negative (TNBC) as previously described [38]. According to the immunohistochemical report, tumor specimens included in this study con- sist of $41(42.7 \%)$ luminal type A, 20 (20.8\%) luminal type B, 19 (19.8\%) HER2-enriched subtype and 16 $(16.7 \%)$ triple-negative breast cancer. As shown in Table 2, stromal TILs significantly differed between subtypes of breast cancer $(p=0.004)$. $77.8 \%$ of triplenegative breast cancer showed intermediate to high infiltration, which is close to HER2-enriched subtype (73.8\%), but much higher than luminal type A (34\%) and B $(52.4 \%)$. These data indicated elevated stromal lymphocytes infiltration in HER2-enriched and TNBC subtypes of breast cancer, which is partly in agreement with our previous findings that the ER/PR negative breast cancers tend to have higher density of TILs.

It has been reported that $\mathrm{Wnt} / \beta$-catenin signaling is upregulated in TNBC [39]. The results showed that cytoplasmic enrichment of $\beta$-catenin in tumor cells was significantly associated with biological subtypes of breast cancer $(p=0.000)$. Among TNBC, $81.2 \%$ of tumor specimens showed positive staining of $\beta$-catenin in the cytoplasm. $73.7 \%$ of HER2-enriched breast cancers were cytoplasmic $\beta$-catenin positive, while in luminal A and luminal B subtypes, the percentages were significantly lower $(56.1 \%$ and $55.0 \%$, respectively), indicating that oncogenic $\mathrm{Wnt} / \beta$-catenin signaling is also upregulated in HER2-enriched breast cancer and TNBC (Table 3). 
Table 2

Comparison of stromal lymphocyte infiltration among molecular subtypes of breast cancer

\begin{tabular}{|c|c|c|c|c|c|}
\hline \multirow[t]{2}{*}{ Subtype } & \multirow{2}{*}{$\begin{array}{c}\text { Number of } \\
\text { patients }(\%)\end{array}$} & \multicolumn{3}{|c|}{ TILs } & \multirow[t]{2}{*}{$\mathrm{p}$} \\
\hline & & Low $(<10 \%)$ & Intermediate (10-40\%) & $\operatorname{High}(\geqslant 40 \%)$ & \\
\hline Luminal A & $41(42.7)$ & $27(66.0)$ & $13(31.9)$ & $1(2.1)$ & 0.004 \\
\hline Luminal B & $20(20.8)$ & $9(47.6)$ & $10(47.6)$ & $1(4.8)$ & \\
\hline HER $2+$ & $19(19.8)$ & $5(26.3)$ & $12(63.2)$ & $2(10.5)$ & \\
\hline TNBC & $16(16.7)$ & $4(22.2)$ & $7(44.5)$ & $5(33.3)$ & \\
\hline
\end{tabular}

Table 3

Comparison of $\beta$-catenin expression among molecular subtypes of breast cancer

\begin{tabular}{|c|c|c|c|c|c|c|c|}
\hline \multirow[t]{2}{*}{ Subtype } & \multirow{2}{*}{$\begin{array}{l}\text { Number of } \\
\text { patients }(\%)\end{array}$} & \multicolumn{2}{|c|}{ Nuclear $\beta$-catenin } & \multirow[t]{2}{*}{$\mathrm{p}$} & \multicolumn{2}{|c|}{ Cytoplasm $\beta$-catenin } & \multirow[t]{2}{*}{$\mathrm{p}$} \\
\hline & & Negative & Positive & & Negative & Positive & \\
\hline Luminal A & $41(42.7)$ & $18(43.9)$ & $23(56.1)$ & 0.051 & $18(43.9)$ & $23(56.1)$ & 0.000 \\
\hline Luminal B & $20(20.8)$ & $10(50.0)$ & $10(50.0)$ & & $9(45.0)$ & $11(55.0)$ & \\
\hline HER $2^{+}$ & $19(19.8)$ & $8(42.1)$ & $11(57.9)$ & & $5(26.3)$ & $14(73.7)$ & \\
\hline TNBC & $16(16.7)$ & $5(31.3)$ & $11(68.7)$ & & $3(18.8)$ & $13(81.2)$ & \\
\hline
\end{tabular}
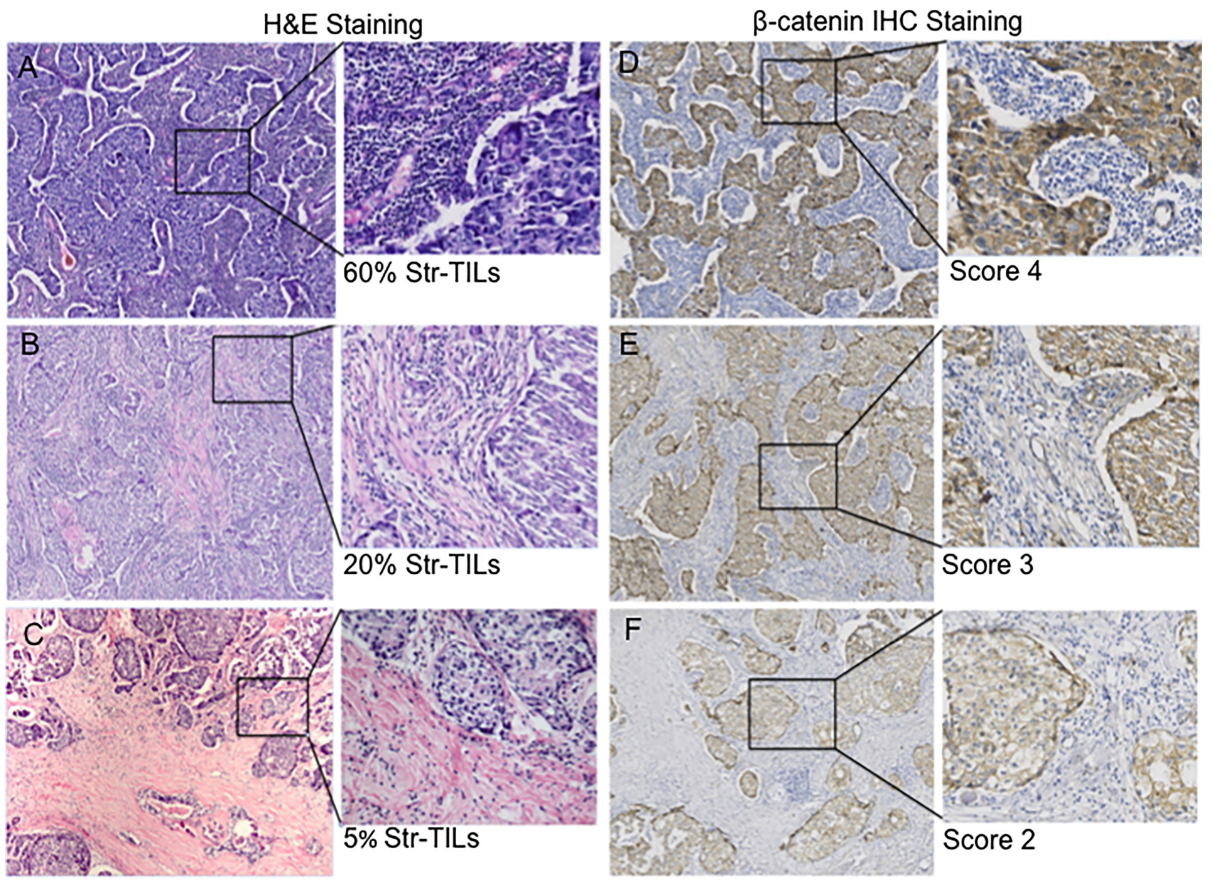

Fig. 3. Correlation between TILs and $\beta$-catenin in breast cancer. Consecutive sections were used for immunohistochemical detection of TILs distribution and $\beta$-catenin expression in breast cancer specimens, and cells were evaluated in the same chosen area of the serial sections. Representative images (A-C) show different levels of lymphocyte infiltration in tumor stroma by H\&E staining. TILs are reported as the percentage of area occupied by mononuclear inflammatory cells over total intratumoral stromal area, within the borders of the invasive tumor. Corresponding sections were stained with $\beta$-catenin antibody by standard IHC techniques (D-F). Scores shown are final staining scores defined according to the $\mathrm{H}$ score of cytoplasmic $\beta$-catenin expression.

\subsection{High levels of TILs are associated with $\beta$-catenin overexpression in breast cancer}

In our study, consecutive sections were used for immunohistochemical detection of TILs distribution and $\beta$-catenin expression in breast cancer specimens, and cells were evaluated in the same chosen area of the serial sections. Representative figures (Fig. 3) showed that tumors with higher lymphocytes infiltration also overexpressed $\beta$-catenin, while in TILs low tumors, $\beta$-catenin was low as well, indicating a positive association between TILs and $\beta$-catenin. We then performed Kruskal-Wallis test to address correlation between $\beta$-catenin expression and stromal lymphocytes 
Table 4

Correlation analyses between presence of stromal TILs and $\beta$-catenin expression in breast cancer

\begin{tabular}{|c|c|c|c|c|c|c|}
\hline & \multicolumn{2}{|c|}{ Nuclear $\beta$-catenin } & \multirow[t]{2}{*}{$\mathrm{p}$} & \multicolumn{2}{|c|}{ Cytoplasm $\beta$-catenin } & \multirow[t]{2}{*}{$\mathrm{p}$} \\
\hline & Negative & Positive & & Negative & Positive & \\
\hline TILs Low $(<10 \%)$ & $33(68.7)$ & $15(31.3)$ & 0.000 & $28(58.3)$ & $20(41.7)$ & 0.000 \\
\hline TILs Intermediate (10-40\%) & $9(22.0)$ & $32(78.0)$ & & $7(17.1)$ & $34(82.9)$ & \\
\hline TILs High $(\geqslant 40 \%)$ & 0 & $7(100)$ & & 0 & $7(100)$ & \\
\hline
\end{tabular}

A

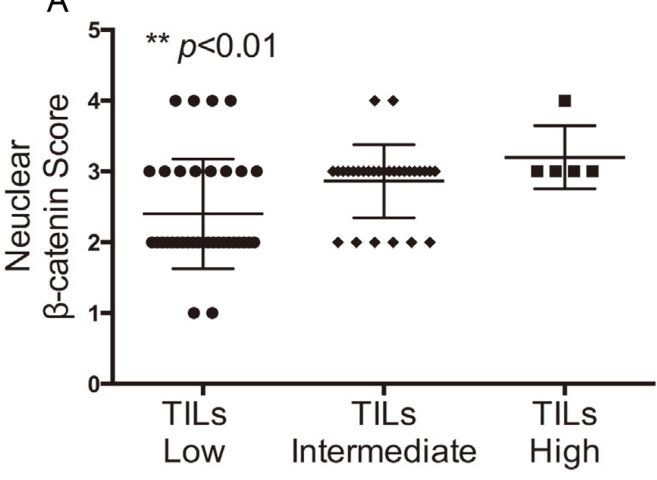

C

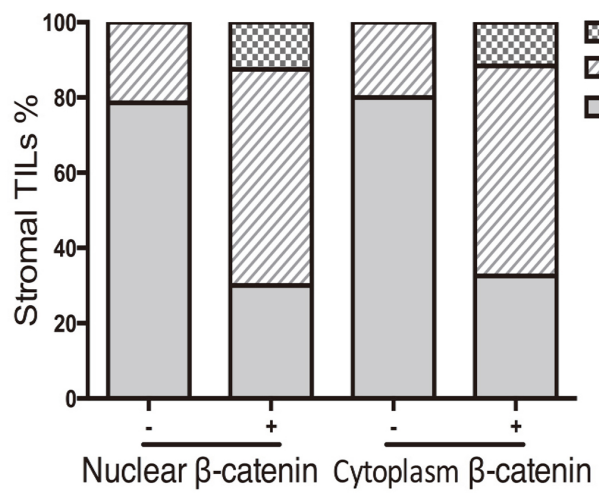

B

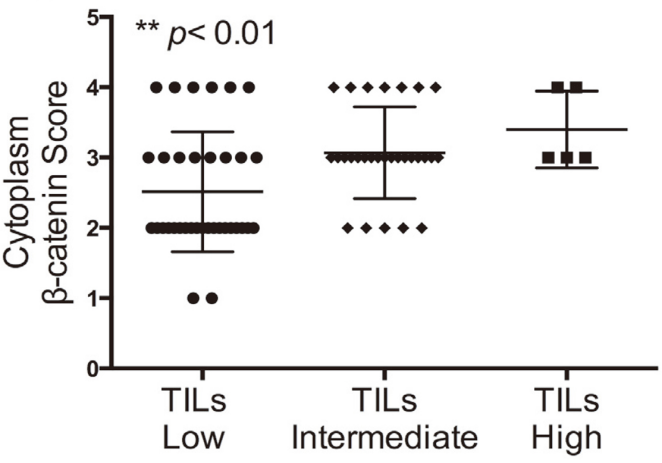

D

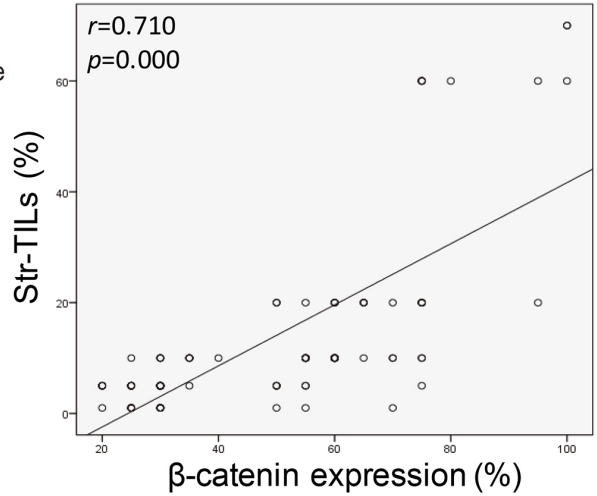

Fig. 4. Correlation of stromal TILs with $\beta$-catenin expression in 96 breast cancer patients. Patients were grouped into 3 main categories, TILs Low $(<10 \%)$, TILs Intermediate $(10-40 \%)$ and TILs High $(\geqslant 40 \%)$ based on the percentage of TILs in tumor stroma. $p<0.01$ represents significant correlations between the level of stromal lymphocytes infiltration and both nuclear $\beta$-catenin (A) and cytoplasm $\beta$-catenin (B) expression Correlation analysis between stromal TILs with $\beta$-catenin expression by using the positive/negative cutoff of $\beta$-catenin expression instead of $\beta$-catenin expression scores (C). Pearson Correlation test were applied for evaluating the correlation between stromal TILs and $\beta$-catenin expression (D).

infiltration in breast cancer. As shown in Fig. 4A and $\mathrm{B}$, both nuclear and cytoplasm $\beta$-catenin expressions were significantly associated with the level of lymphocytes infiltration in breast cancer $(p<0.01)$. When we applied the- positive/negative cutoff of $\beta$-catenin instead of $\beta$-catenin scores, the results again confirmed that tumors with $\beta$-catenin overexpression tend to have higher level of lymphocytes infiltration (Fig. 4C and Table 4). Moreover, there was a linear correlation between $\beta$-catenin expression and TILs level $(r=0.710$, $p<0.001)$ as shown by Pearson correlation analysis (Fig. 4D).

\subsection{Association of $\mathrm{CD}^{+}$and FOXP3 ${ }^{+}$TIL subsets infiltration with $\beta$-catenin expression in breast cancer}

We further assessed the association of two TIL subsets, $\mathrm{CD}^{+}$and $\mathrm{FOXP}^{+}{ }^{+}$T cells with $\beta$-catenin expression in all the 96 breast cancer samples. Both $\mathrm{CD}^{+} \mathrm{T}$ cells $(r=0,682, p=0.000)$ and FOXP3 ${ }^{+}$ Tregs $(r=0.450, p=0.000)$ infiltration were associated significantly with stromal TILs in breast cancer (Fig. 5A and B). Pearson correlation revealed a linear correlation between $\mathrm{CD}^{+} \mathrm{T}$ cells $(r=0.577, p=$ 
A

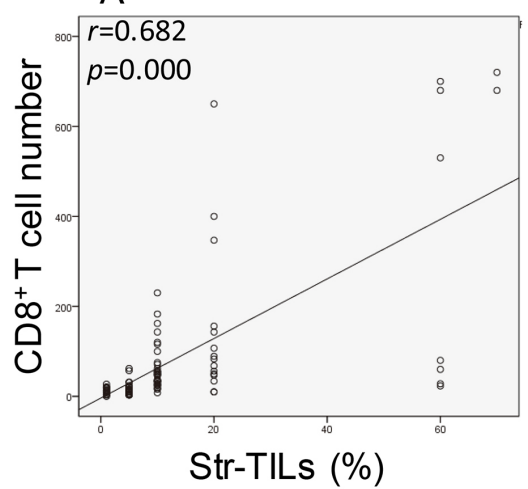

B

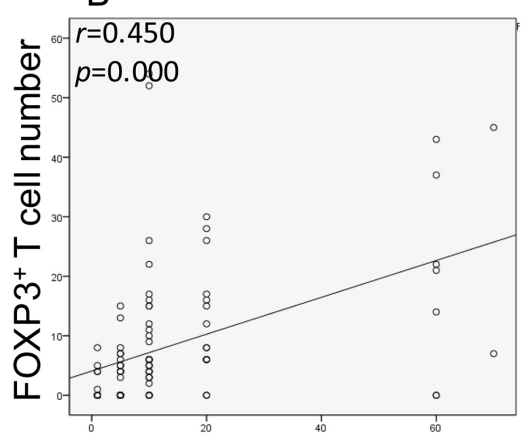

Str-TILs (\%)

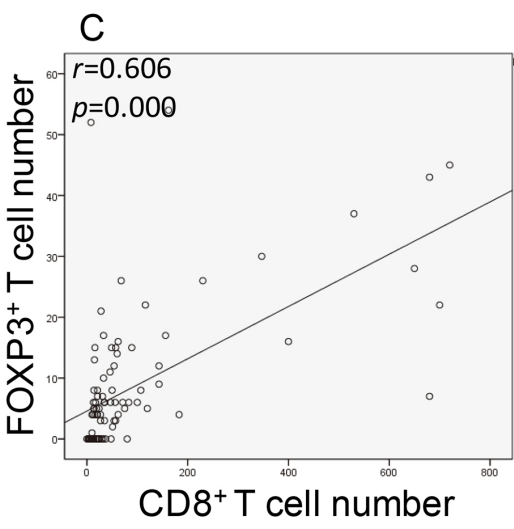

\section{$\mathrm{E}$}
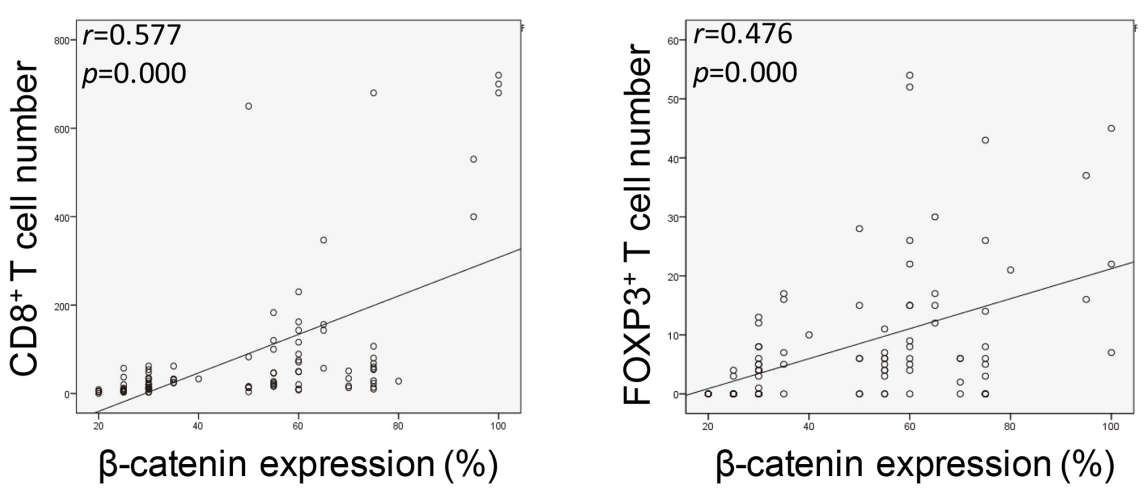

Fig. 5. Association of TIL subsets infiltration with $\beta$-catenin expression in breast cancer. Correlation of stroma TILs with CD8 ${ }^{+}$T cells (A) or $\mathrm{FOXP}^{+} \mathrm{T}$ cell (B) infiltration; correlation between $\mathrm{CD} 8^{+} \mathrm{T}$ cells and FOXP3 ${ }^{+} \mathrm{T}$ cell infiltration $(\mathrm{C})$ and the correlation of $\beta$-catenin expression with $\mathrm{CD}^{+} \mathrm{T}$ cells $(\mathrm{D})$ or FOXP3 ${ }^{+} \mathrm{T}$ cell $(\mathrm{E})$ were analyzed by Pearson Correlation test.

$0.000) / \mathrm{FOXP}^{+}$Tregs $(r=0.476, p=0.000)$ and the expression of $\beta$-catenin by tumor cells (Fig. 5C and D). Intriguingly, the presence of FOXP3 ${ }^{+}$Tregs in tumor stroma was positively associated with the infiltration by $\mathrm{CD}^{+} \mathrm{T}$ cells $(r=0.606, p=0.000)$ (Fig. $\left.5 \mathrm{E}\right)$.

\section{Discussion}

TILs that interact with other immune infiltrates in the tumor microenvironment are mainly responsible for intratumoral immune responses. Detection of TILs by immunohistochemical techniques may be an indicator of immune responses to cancer development. In addition, presence of TILs shows predictive value for patients' responses to neoadjuvant chemotherapy and can potentially help oncologists to identify the subgroup of patients that will receive greater benefit from the therapy [40,41]. Rather than showing clinical significance among overall breast cancer population, the prognostic or predictive values of TILs seems to be restricted for certain molecular subtypes of breast cancer, mainly TNBC and HER2-enriched subtypes [42,43]. Our clinicopathological data revealed significant correlations between ER/PR status and stromal TILs. ER/PR negative $\mathrm{BC}$ i.e. TNBC or HER2-positive $\mathrm{BC}$ tends to have higher level of lymphocytes infiltration, while in luminal type $\mathrm{A}$ and $\mathrm{B}$, the percentage is much lower. These results are partly consistent with previous data form other studies [5,8] showing that the clinical value of TILs should be emphasized in hormone receptor negative BC, i.e. TNBC and HER2 ${ }^{-}$enriched BCs. We suggest that not only using hormone receptors for defining cancer subtypes, further research into how hormone activity may affect lymphocytes recruitment in $\mathrm{BC}$ is warranted.

$\beta$-catenin is the central player in canonical $\mathrm{Wnt} / \beta$ catenin pathway. It is mainly involved in regulation of cell-cell adhesion and transcription for a wide rage of genes. In the absence of Wnt signaling, the $\beta$ catenin protein is constitutively degraded by the $\beta$ catenin destruction complex. When activated by Wnt 
ligands, co-activation of the Frizzled and low-density lipoprotein receptor-related proteins (LRP) receptors induces the inhibition of the destruction complex and the consequent stabilization of $\beta$-catenin in the cytoplasm. $\beta$-catenin eventually translocates in nuclear, where it modulates expression of a broad range of target genes [44]. $\beta$-catenin accumulates in various malignant tumors, which is related to abnormal activation of the $\mathrm{Wnt} / \beta$-catenin pathway during carcinogenesis and tumor progression $[45,46]$. Alterations of $\mathrm{Wnt} / \beta$ catenin signaling also present in more than $60 \%$ of breast cancer and may predict unfavorable disease outcome [47].

$\mathrm{Wnt} / \beta$-catenin pathway provides important proliferative and maintenance signals, which regulate selfrenewal of hematopoietic stem cells and the development of lymphocytes [11,48-51]. Later on, increasing studies indicated that $\mathrm{Wnt} / \beta$-catenin signaling exerts significant effects on tumor immune system. It induces immune suppression and resistance by regulating some key cytokines [17] and the function of immune cells [52]. In melanoma, tumour-intrinsic activation of $\beta$-catenin signalling results in T-cell exclusion and resistance to anti-PD-L1/anti-CTLA-4 monoclonal antibody immunotherapy [21]. These findings suggested that deregulation of $\mathrm{Wnt} / \beta$-catenin pathway in malignant tumors may contribute to cancer immune evasion and resistance to immunotherapies.

By IHC staining of $\beta$-catenin in breast cancer specimens, we first report an association between $\mathrm{Wnt} / \beta$ catenin signaling and lymphatic infiltration in human breast cancer. Cytoplasmic and/or nuclear accumulation of $\beta$-catenin in tumor nest was observed in all the 96 invasive breast cancer samples. By consecutive section staining, we noticed that rather than preventing $\mathrm{T}$ cell infiltration into tumor site, overexpression of $\beta$ catenin in cancer cells was associated with higher TILs density in the stroma. Moreover, a linear correlation between $\beta$-catenin expression and TILs level was identified $(r=0.710, p<0.001)$. These results are surprisingly inconsistent with current knowledge reported in melanoma [21]. This can be partly explained by the fact that Wnt- $\beta$-catenin pathway may function differently depending on the distinct biological backgrounds of cancers. Besides, comparative gene expression profiling instead of IHC staining for TILs was used in their study, which may lead to different results as well. However, our observations again raised the question whether tumor intrinsic Wnt- $\beta$-catenin signaling only displays unfavorable effects on anti-tumor immune response. According to studies of Forget et al. [24] and
Gattinoni et al. [49], Wnt/ $\beta$-catenin signaling plays a key role in the maintenance of stemness and promoted $\mathrm{T}_{S C M}$ subset in mature memory $\mathrm{CD}^{+} \mathrm{T}$ cells from both TILs and the periphery, indicating that the function of $\mathrm{Wnt} / \beta$-catenin pathway in vivo may be beneficial for the improvement of adoptive immunotherapies. Since the H\&E staining method only locates mononuclear TILs but is limited in revealing the functional status of lymphocytes, further investigations concerning the biology characteristics of human TILs and its correlation with $\mathrm{Wnt} / \beta$-catenin activity are required.

Different subgroups of the immune complex within tumor site may exert diverse functions. For example, DCs, Th1 CD4 ${ }^{+} \mathrm{T}$ cells and cytotoxic $\mathrm{CD}^{+} \mathrm{T}$ cells are found to be involved in anticancer immunosurveillance. In contrast, Th17 CD4 ${ }^{+} \mathrm{T}$ cells and FOXP3 ${ }^{+}$ $\mathrm{CD}^{+}{ }^{+}$regulatory $\mathrm{T}$ cells (Tregs) function in the context of protumorigenic inflammation [54]. In recent years, the bulk of studies suggested that distinct infiltrating cell types have distinct prognostic and potentially predictive significance [54]. In BC, high level of $\mathrm{CD}^{+}$lymphocyte infiltration indicates better prognosis of patients, while high density of FOXP3 ${ }^{+}$Tregs are often associated with poor survival outcomes [42]. These findings suggest the possibility that $\mathrm{Wnt} / \beta$ catenin pathway may function differently on these two TIL subsets. We found that in all the 96 specimens, densities of $\mathrm{CD}^{+} \mathrm{T}$ cells are much higher than $\mathrm{FOXP}^{+}$lymphocytes. Both $\mathrm{CD}^{+}{ }^{+}$and FOXP3 ${ }^{+}$TILs densities were positively correlated with total stromal TILs ( $r=0.682, P<0.001 ; r=0.450, P<0.001)$. West et al. [55] argued that despite the well-accepted fact that $\mathrm{FOXP}^{+}$and $\mathrm{CD} 8^{+} \mathrm{T}$ cells function contradictorily during anti-tumour immune responses, the prognostic value of FOXP3 ${ }^{+}$TILs for breast cancer is dependent of the presence of $\mathrm{CD}^{+}$TILs. Notably, our results indicated that FOXP3 ${ }^{+}$TILs number is significantly associated with the total $\mathrm{CD}^{+}$infiltrates in tumor stroma $(r=0.606, P<0.001)$, which is consistent with the previous report [52]. It is unclear at present why $\mathrm{CD}^{+}$TILs still exert anti-tumor effects and are associated with better prognosis when coinfiltrating with a large number of FOXP $3^{+}$Tregs. According to some in vitro models, Tregs require close contact with target cells to induce immune suppression [56]. Besides, the interactions of TILs with tumor cells and stromal cells within tumor microenvironment are extremely complicated. When using CD25 as the molecular marker of Tregs, Prat et al. [57] demonstrated that markers of dendritic cell activation, inflammatory cytokine production and $\mathrm{CD} 8^{+} \mathrm{T}$-cell cytotox- 
icity were enriched in CD25-high breast tumors, suggesting a complex of anti-tumour immunity can be active in breast tumors despite the presence of Tregs. In our case, the analysis of Tregs-CD8 ${ }^{+}$TILs interaction within tumor site is demanded in order to interpret the functional status of TILs. And looking into multiple components of TILs instead of focusing on certain lymphocytes should be considered. At last, we analyzed the correlation between $\mathrm{CD}^{+} / \mathrm{FOXP}^{+} \mathrm{TIL}$ subsets and tumor intrinsic $\beta$-catenin over-expression. Based on our findings, it can not be concluded whether $\mathrm{Wnt} / \beta$-catenin pathway functions differently on these two TIL subgroups, since both the number of CD8 ${ }^{+}$ T cells $(r=0.577, P<0.001)$ and FOXP3 ${ }^{+} \mathrm{T}$ cells $(r=0.476, P<0.001)$ are positively associated with abnormal $\beta$-catenin expression in breast cancer. Moreover, our results did not support the report that activation of $\mathrm{Wnt} / \beta$-catenin signaling excluded $\mathrm{T}$ cell infiltration in tumor [21]. Nevertheless, our findings demonstrated a significant association of $\mathrm{Wnt} / \beta$ catenin pathway with total TILs and two TIL subgroups in breast cancer, indicating that $\mathrm{Wnt} / \beta$-catenin pathway is potentially involved in tumor immunosurveillance and anti-tumor immunity. Further studies are demanded to verify these findings and to explore the underlined mechanisms.

To sum up, our results demonstrated that lymphocytes infiltration in tumor stroma varies with hormone receptor status, tumor grade and different molecular subtypes of breast cancer. Both stromal lymphocytes infiltration and $\beta$-catenin expression were more enriched in TNBC and HER2 positive BCs. Rather than excluding lymphocytes infiltration as reported in melanoma, we found that high levels of TILs were associated with $\beta$-catenin overexpression in $\mathrm{BC}$. And both the number of $\mathrm{CD}^{+}$CTLs and FOXP3 ${ }^{+} \mathrm{T}$ cells were positively associated with abnormal $\beta$-catenin expression. Further studies to explore the effects of $\mathrm{Wnt} / \beta$-catenin pathway on breast cancer immunity and the functional status of CTLs and Tregs in different breast cancer subtypes will lead us to better understand tumor-TILs interaction mechanisms and provide therapeutic targets for the improvement of immunotherapy of breast cancer.

\section{Acknowledgments}

This work was supported by the National Natural Science Foundation of China (Project No.81274136).

\section{References}

[1] K.D. Miller, R.L. Siegel, C.C. Lin et al., Cancer treament and survivorship statistics, CA Cancer J Clin 66(4) (2016), 271289.

[2] J. Ferlay, I. Soerjomataram, R. Dikshit et al., Cancer incidence and mortality worldwide: sources, methods, major patterns in GLOBOCAN 2012, Int J Cancer 136(5) (2015), E359-E386.

[3] R.D. Schreiber, L.J. Old and M.J. Smyth, Cancer immunoediting: integrating immunity's roles in cancer suppression and promotion, Science 331 (2011), 1565-1570.

[4] L. Carbognin, S. Pilotto, R. Nortilli et al., Predictive and Prognostic Role of Tumor-Infiltrating Lymphocytes for Early Breast Cancer According to Disease Subtypes: Sensitivity Analysis of Randomized Trials in Adjuvant and Neoadjuvant Setting, Oncologist 21(3) (2016), 283-291.

[5] M.V. Dieci, M.C. Mathieu, V. Guarneri et al., Prognostic and predictive value of tumor-infiltrating lymphocytes in two phase III randomized adjuvant breast cancer trials, Ann Oncol 26(8) (2015), 1698-1704.

[6] S. Adams, R.J. Gray and S. Demaria et al., Prognostic value of tumor-infiltrating lymphocytes in triple-negative breast cancers from two phase III randomized adjuvant breast cancer trials: ECOG 2197 and ECOG 1199, J Clin Oncol 32(27) (2014), 2959-2966.

[7] C. Denkert, S. Loibl, A. Noske et al., Tumor-associated lymphocytes as an independent predictor of response to neoadjuvant chemotherapy in breast cancer, $J$ Clin Oncol 28(1) (2010), 105-113.

[8] S. Loi, S. Michiels, R. Salgado et al., Tumor infiltrating lymphocytes are prognostic in triple negative breast cancer and predictive for trastuzumab benefit in early breast cancer: results from the FinHER trial, Ann Oncol 25(8) (2014), 15441550 .

[9] D.J. Van Den Berg, A.K. Sharma, E. Bruno et al., Role of members of the Wnt gene family in human hematopoiesis, Blood 92(9) (1998), 3189-3202.

[10] F.J. Staal, J. Meeldijk, P. Moerer et al., Wnt signaling is required for thymocyte development and activates Tcf-1 mediated transcription, Eur J Immunol 31 (2001), 285-293.

[11] F.J. Staal, T.C. Luis and M.N. Tiemessen, WNT signalling in the immune system: WNT is spreading its wings, Nature Reviews Immunology 8 (2008), 581-593.

[12] L. Gattinoni, Y. Ji and N.P. Restifo, Wnt/beta-catenin signaling in T-cell immunity and cancer immunotherapy, Clin Cancer Res 16(19) (2010), 4695-4701.

[13] G. Driessens, Y. Zheng, F. Locke et al., $\beta$-Catenin Inhibits $\mathrm{T}$ Cell Activation by Selective Interference with Linker for Activation of T Cells-Phospholipase C- $\gamma 1$ Phosphorylation, J Immunol 186(2) (2011), 784-790.

[14] S. Muralidharan, P.J. Hanley, E. Liu et al., Activation of Wnt signaling arrests effector differentiation in human peripheral and cord blood-derived T lymphocytes, J Immunol 187(10) (2011), 5221-5232.

[15] C. Oderup, M. LaJevic and E.C. Butcher, Canonical and noncanonical Wnt proteins program dendritic cell responses for tolerance, J Immunol 190(12) (2013), 6126-6134.

[16] T. Reya and H. Clevers, Wnt signalling in stem cells and cancer, Nature 434(7035) (2005), 843-850.

[17] T. Yaguchi, Y. Goto and K. Kido et al., Immune Suppression and Resistance Mediated by Constitutive Activation of Wnt $\beta$-Catenin Signaling in Human Melanoma Cells, $J$ Immunol 189(5) (2012), 2110-2117. 
[18] H. Harlin, Y. Meng, A.C. Peterson et al., Chemokine expression in melanoma metastases associated with CD81 T-cell recruitment, Cancer Res 69(7) (2009), 3077-3085.

[19] R.R. Ji, S.D. Chasalow, L. Wang et al., An immune-active tumor microenvironment favors clinical response to ipilimumab, Cancer Immunol Immunother 61(7) (2012), 10191031 .

[20] O. Hamid and R.D. Carvajal, Anti-programmed death-1 and anti-programmed death-ligand 1 antibodies in cancer therapy, Expert Opin Biol Ther 13(6) (2013), 847-861.

[21] S. Spranger, R. Bao and T.F. Gajewski, Melanoma-intrinsic $\beta$-catenin signalling prevents anti-tumour immunity, Nature 523(7559) (2015), 231-235

[22] H.E. Fleming, V. Janzen, C. Lo Celso et al., Wnt signaling in the niche enforces hematopoietic stem cell quiescence and is necessary to preserve self-renewal in vivo, Cell Stem Cell 2 (2008), 274-283

[23] A.W. Duncan, F.M. Rattis, L.N. DiMascio et al., Integration of Notch and Wnt signaling in hematopoietic stem cell maintenance, Nat Immunol 6(3) (2005), 314-322.

[24] M.A. Forget, Y. Huon, A. Reuben et al., Stimulation of $\mathrm{Wnt} / \beta$-catenin pathway in human $\mathrm{CD}^{+} \mathrm{T}$ lymphocytes from blood and lung tumors leads to a shared young/memory phenotype, PLoS One 7(7) (2012), e41074.

[25] S.Y. Lin, W. Xia, J.C. Wang et al., Beta-catenin, a novel prognostic marker for breast cancer: its roles in cyclin D1 expression and cancer progression, Proc Natl Acad Sci USA 97(8) (2000), 4262-4266.

[26] A.I. Khramtsov, G.F. Khramtsova and M. Tretiakova et al., Wnt/beta-catenin pathway activation is enriched in basal-like breast cancers and predicts poor outcome, Am J Pathol 176(6) (2010), 2911-2920.

[27] X. Ma, W. Yan, Z. Dai et al., Baicalein suppresses metastasis of breast cancer cells by inhibiting EMT via downregulation of SATB1 and Wnt/ $\beta$-catenin pathway, Drug Des Devel Ther 10 (2016), 1419-1441.

[28] S.M. Mahmoud, E.C. Paish, D.G. Powe et al., TumorInfiltrating $\mathrm{CD}^{+}$Lymphocytes Predict Clinical Outcome in Breast Cancer, J Clin Oncol 29(15) (2011), 1949-1955.

[29] F. Liu, R. Lang, J. Zhao et al., CD8 ${ }^{+}$cytotoxic $\mathrm{T}$ cell and $\mathrm{FOXP}^{+}{ }^{+}$regulatory $\mathrm{T}$ cell infiltration in relation to breast cancer survival and molecular subtypes, Breast Cancer Res Treat 130 (2011), 645-655. BMC Cancer 15 (2015), 727.

[30] S. Liu, J. Lachapelle, S. Leung et al., CD8 ${ }^{+}$lymphocyte infiltration is an independent favorable prognostic indicator in basal-like breast cancer, Breast Cancer Research 14 (2002), R48.

[31] G.J. Bates, S.B. Fox, C. Han et al., Quantification of regulatory $\mathrm{T}$ cells enables the identification of high-risk breast cancer patients and those at risk of late relapse, J Clin Oncol $\mathbf{2 4}$ (2006), 5373-5380

[32] D. Jiang, Z. Gao, Z. Cai et al., Clinicopathological and prognostic significance of FOXP3 ${ }^{+}$tumor infiltrating lymphocytes in patients with breast cancer: a meta-analysis, $B M C$ Cancer 15 (2015), 727.

[33] M.E. Hammond, D.F. Hayes, A.C. Wolff et al., American Society of Clinical Oncology/College Of American Pathologists guideline recommendations for immunohistochemical testing of estrogen and progesterone receptors in breast cancer, J Clin Oncol 28(16) (2010), 2784-2795.

[34] A.C. Wolff, M.E. Hammond, D.G. Hicks et al., Recommendations for human epidermal growth factor receptor 2 testing in breast cancer: American Society of Clinical Oncol-
ogy/College of American Pathologists clinical practice guideline update, J Clin Oncol 31(31) (2013), 3997-4013.

[35] R. Salgado, C. Denkert and S. Demaria et al., The evaluation of tumor-infiltrating lymphocytes (TILs) in breast cancer: recommendations by an International TILs Working Group 2014, Annals of Oncology 26 (2014), 259-2571.

[36] E. Lóez-Knowles, S.J. Zardawi, C.M. McNeil et al., Cytoplasmic Localization of $\beta$-Catenin is a Marker of Poor Outcome in Breast Cancer Patients, Cancer Epidemiol Biomarkers Prev 19(1) (2010), 301-309.

[37] L. Demir, S. Yigit, H. Ellidokuz et al., Predictive and prognostic factors in locally advanced breast cancer: effect of intratumoral FOXP3 ${ }^{+}$Tregs, Clin Exp Metastasis 30 (2013), 1047-1062.

[38] O. Yersal and S. Barutca, Biological subtypes of breast cancer: Prognostic and therapeutic implications, World J Clin Oncol 5(3) (2014), 412-424.

[39] N. Dey, B.G. Barwick, C.S. Moreno et al., Wnt signaling in triple negative breast cancer is associated with metastasis, BMC Cancer 13 (2013), 537.

[40] C. Denkert, S. Loibl, A. Noske et al., Tumor-associated lymphocytes as an independent predictor of response to neoadjuvant chemotherapy in breast cancer, J Clin Oncol 28(1) (2010), 105-113.

[41] H. Hornychova, B. Melichar, M. Tomsova et al., Tumorinfiltrating lymphocytes predict response to neoadjuvant chemotherapy in patients with breast carcinoma, Cancer Invest 26(10) (2008), 1024-1031.

[42] Y. Mao, Q. Qu, X. Chen et al., The Prognostic Value of Tumor-Infiltrating Lymphocytes in Breast Cancer: A Systematic Review and Meta-Analysis, PLoS One 11(4) (2016), e0152500.

[43] L. Carbognin, S. Pilotto, R. Nortilli et al., Predictive and Prognostic Role of Tumor-Infiltrating Lymphocytes for Early Breast Cancer According to Disease Subtypes: Sensitivity Analysis of Randomized Trials in Adjuvant and Neoadjuvant Setting, Oncologist 21(3) (2016), 283-291.

[44] R. Fodde and T. Brabletz, Wnt/beta-catenin signaling in cancer stemness and malignant behavior, Curr Opin Cell Biol 19(2) (2007), 150-158.

[45] M. Krausova and V. Korinek, Wnt signaling in adult intestinal stem cells and cancer, Cell Signal 26(3) (2014), 570-579.

[46] Z. Wang, H. Zhang, J. Hou et al., Clinical implications of $\beta$-catenin protein expression in breast cancer, Int J Clin Exp Pathol 8(11) (2015), 14989.

[47] N. Mukherjee, N. Bhattacharya, N. Alam et al., Subtypespecific alterations of the Wnt signaling pathway in breast cancer: clinical and prognostic significance, Cancer Sci 103(2) (2012), 210-220.

[48] F.J. Staal and H.C. Clevers, WNT signalling and hematopoiesis: a WNT-WNT situation, Nat Rev Immuno 5(1) (2005), 21-30

[49] L. Gattinoni, X.S. Zhong, D.C. Palmer et al., Wnt signaling arrests effector $\mathrm{T}$ cell differentiation and generates $\mathrm{CD}^{+}$ memory stem cells, Nat Med 15 (2009), 808-813.

[50] D.M. Zhao, S. Yu and X. Zhou et al., Constitutive activation of Wnt signaling favors generation of memory CD8 T cells, $J$ Immunol 184 (2010), 1191-1199.

[51] D. Notani, K.P. Gottimukkala, R.S. Jayani et al., Global regulator SATB1 recruits beta-catenin and regulates $\mathrm{T}(\mathrm{H}) 2$ differentiation in Wnt-dependent manner, PLoS Biol 8 (2010), e1000296. 
[52] X. Liang, C. Fu, W. Cui et al., $\beta$-catenin mediates tumorinduced immunosuppression by inhibiting cross-priming of $\mathrm{CD}^{+}{ }^{+}$T cells, J Leukoc Biol 95(1) (2014), 179-190.

[53] W.H. Fridman, J. Galon and F. Pagès et al., Prognostic and predictive impact of intra- and peritumoral immune infiltrates, Cancer Res 71(17) (2011), 5601-5605.

[54] J. Galon, H.K. Angell, D. Bedognetti et al., The Continuum of Cancer Immunosurveillance: Prognostic, Predictive, and Mechanistic Signature, Immunity 39(1) (2013), 11-26.
[55] N.R. West, S.E. Kost, S.D. Martin et al., Tumour-infiltrating $\mathrm{FOXP}^{+}{ }^{+}$lymphocytes are associated with cytotoxic immune responses and good clinical outcome in oestrogen receptornegative breast cancer, Br J Cancer 108(1) (2013), 155-162.

[56] E.M. Shevach, Mechanisms of FOXP3 ${ }^{+} \mathrm{T}$ regulatory cellmediated suppression, Immunity 30(5) (2009), 636-645.

[57] A. Prat, J.S. Parker and O. Karginova et al., Phenotypic and molecular characterization of the claudin-low intrinsic subtype of breast cancer, Breast Cancer Res 12(5) (2010), R68. 